\title{
Conceptualización de la Reputación Corporativa. Nuevo enfoque y propuesta
}

Conceptualisation of Corporate Reputation. New approach and proposal

\author{
Sonia Aránzazu Ferruz González, Universidad Complutense de Madrid - sferruz@ucm.es
}

\section{Resumen}

La reputación corporativa ha alcanzado en la última década un protagonismo que la ha llevado a ser objeto de numerosos estudios desde el ámbito académico y también desde el profesional. En lo que se refiere a su conceptualización hay distintos enfoques que estudian este intangible desde la comunicación y la teoría empresarial. Partiendo de la hipótesis de que el concepto de reputación necesita una clarificación y definición más ajustada a la gestión actual del negocio, el presente estudio analiza las teorías y trabajos académicos presentados en Europa y América en los últimos 30 años, comparándolos y estableciendo los elementos configuradores de la reputación corporativa para proponer una definición de consenso.

Palabras clave

Reputación corporativa; concepto reputación; gestión reputacional.

Abstract

Corporate reputation has reached along last decade a prominence place that has driven it to be deeply studied both from the academic and professional fields. Regarding its definition, there are different approaches from the communication and business spheres. Assuming as starting-point that corporate reputation concept needs a clarification and a definition that explain better the current business management, the study analyses the theories presented in the last 30 years in Europe and America, comparing them and defining the elements that configures the concept of corporate reputation in order to propose a consensus definition of it.

Keywords

Corporate Reputation; reputation concept; reputational management.

Sumario

1. Introducción. 2. Metodología y objetivos. 3. Revisión de la literatura. 3.1. Concepto general de reputación. 3.2. Concepto de reputación corporativa. 4. Conclusiones: nueva propuesta conceptual de Reputación corporativa. 5. Bibliografía. 


\section{Introducción}

El término "clásico" de reputación viene usándose desde antiguo para referirse a aquello por lo que se conoce a una persona, lo que se dice de ella en los mentideros y que viene precedido de un comportamiento o unos hechos que han provocado esa reputación. Así, por ejemplo, los Tercios Españoles, se labraron una reputación, que todavía hoy perdura, como la mejor infantería europea durante casi 150 años; o la más reciente de Dalí como personaje ultra esnob, por citar alguno de los muchos casos conocidos. En todos ellos, la reputación emerge como consecuencia de los hechos que tales personas u organizaciones realizan y que se van comentando de boca en boca, creando una opinión, individual primero y colectiva después, y que puede ser buena o mala, en tanto que responde a unos hechos que se valoran de forma positiva o negativa de acuerdo a los valores sociales compartidos. La reputación así entendida ha venido reconociéndose durante siglos. Sócrates la definió en el siglo V a.C. con sencillez y exactitud (Walter, 1999, p. 460): ("Alcanzarás buena reputación esforzándote en ser lo que quieres parecer"). El estallido de la sociedad de consumo tal y como la conocemos desde mediados del siglo XX supuso el resurgimiento académico del concepto de reputación vinculado a la gestión empresarial -reputación corporativa-, pero relacionándolo íntimamente con la imagen corporativa. En la actualidad, todavía existe controversia en su definición y en su consideración como activo que dota de valor a las empresas.

\section{Metodología y objetivos}

El estudio se centra en la revisión de toda la teoría sobre el concepto objeto de estudio -la reputación corporativa- y la exposición de la problemática existente y los diferentes puntos de vista y/o definiciones más relevantes, con el objetivo de realizar un análisis comparativo de los elementos configuradores de los distintos planteamientos para proponer un nuevo concepto de consenso.

\section{Revisión de la literatura}

\subsection{Concepto general de reputación}

La reputación unida al concepto de credibilidad es, desde antiguo, la base de la participación en la vida política y pública. Aristóteles la presentaba como el "mayor de los bienes exteriores" y resultado de la virtud (premium virtutis, tradujo Cicerón). La idea y el hecho de la credibilidad como virtud pública, fuente de reputación, recorre todo el pensamiento occidental hasta nuestros días (Álvarez, 2013, introducción). Más en nuestros días y de acuerdo al Diccionario de la Real Academia Española de la Lengua (Diccionario de la Lengua Española, 2001) reputación, que proviene del latín reputatio,-ōnis tiene dos acepciones:

\section{1. f. Opinión o consideración en que se tiene a alguien o algo.}

2. f. Prestigio o estima en que son tenidos alguien 0 algo.

Como vemos, la primera explica en parte el concepto original de reputación en tanto que habla de opinión o consideración, pero no menciona el vínculo de ésta con las acciones o hechos que la provocan. Y la segunda, por su parte, concreta más esa opinión matizándola como "prestigio o estima" es decir, dándole una connotación directamente positiva. Por tanto, en ninguna de ellas se hace referencia a que la reputación se derive de un acto realizado por alguien o algo, lo que dista del uso del concepto mencionado anteriormente.

Algunos autores citan la segunda acepción del término como la noción común de la que se desprenden los rasgos que mantendrá la definición científica del término (Alloza, Carreras y Carreras, 2013, pp.66-67): «La reputación es una propiedad de la audiencia, un juicio de valor que tiene la audiencia sobre la persona u objeto».

Veamos que significa la acción de creación de reputación, es decir, reputar, de nuevo, de acuerdo al Diccionario de la Real Academia Española de la Lengua, encontramos dos acepciones:

(Del lat. reputāre)

1. tr. Juzgar o hacer concepto del estado o calidad de alguien o algo. U. t. c. prnl.

2. tr. Apreciar o estimar el mérito.

Comprobamos aquí sí, en la segunda acepción, que existe un vínculo directo entre la acción y la consecuencia de la misma, en tanto que reputar hace referencia al aprecio o la estima del mérito, y éste, directamente a la acción que hace al hombre digno de premio o de castigo, 0 al resultado de las buenas acciones que hacen digna de aprecio a una persona (de acuerdo también al Diccionario de la Lengua Española). Y si reputar es apreciar o estimar el mérito, reputación como consecuencia del acto de reputar, debiera ser el resultado de esa apreciación o estimación basada en las acciones que lo han hecho digno de mérito (o demérito). Por tanto, el concepto de reputación parece haber perdido una parte fundamental de su definición, la que le supedita directamente a los hechos que la provocan.

En el presente estudio se toma en consideración la definición clásica de reputación como la acepción fundamental para entender y explicar su aplicación al ámbito empresarial (reputación corporativa).

\subsection{Concepto de Reputación Corporativa}

El nacimiento de los medios de comunicación de masas a mediados del siglo XX y sobre todo su expansión posterior y el paralelo crecimiento exacerbado de las herramientas del marketing y la publicidad, han servido de perfectos instrumentos al servicio de la imagen y 
El estudio y conceptualización de la reputación aplicada al ámbito empresarial o reputación corporativa entendida esta como la que se refiere a las corporaciones, viene siendo objeto de debate desde hace varias décadas y, especialmente, desde los años 90 del pasado siglo, donde numerosos teóricos, en su mayoría del ámbito de la comunicación pero también de la economía, el marketing y las ciencias empresariales, han tratado de definirla (Balmer y Greyser, 2006; Barnett et al., 2006; Bromley, 2002; Caruana y Chircop, 2000; Chun, 2005; Deephouse, 2000; Gotsi y Wilson, 2001; Helm, 2005; Herbig and Milewicz, 1993; Caruana en Melewar, 2008; Ponzi et al., 2011; Pruzan, 2001; Schwaiger, 2004; Shenkar and Yuchtman-Yaar, 1997; Van Riel y Fombrun, 2007; Villafañe, 2004, Weigelt y Camerer, 1988). En algunos casos las definiciones tienen aspectos en común y en otros son contradictorias. Para algunos autores, estamos ante una «Torre de Babel» (Hatch and Schultz, 2000, pp. 12-35) o una «niebla conceptual» (Balmer, 2001, pp. 248-291) y existe claramente un problema de consenso en la definición de reputación en la literatura académica.

Varios de estos teóricos datan el origen del concepto de reputación corporativa en 1958 en el artículo de Pierre Martineau (1958, p. 53). Martineau teoriza sobre el concepto de imagen corporativa por primera vez e introduce aspectos muy relevantes, pero ciertamente no habla en ningún caso de reputación. Estos autores, sin embargo, dado que consideran la imagen corporativa como el «alma» de la reputación, toman el escrito de Martineau como punto de referencia. Tras dicho texto, durante las dos décadas siguientes se produce un vacío en cuanto al estudio de la reputación aplicada al ámbito empresarial. Algunos autores denominan a esta etapa «el desencanto» (Brown y Dacin, 1997, p. 69), por la escasez de producción científica motivada por el auge de los estudios vinculados a los efectos de la publicidad sobre la audiencia (imagen de marca y preferencia de compra, etc.).

En la década de los 60 y 70, los estudios sobre la imagen corporativa eran un campo de investigación muy atractivo, mientras que el término reputación corporativa no era muy común en la literatura de comunicación y marketing de esa época. Estos planteamientos se han mantenido en muchos autores hasta la actualidad. En este sentido, la similitud (planteada como conceptos sinónimos) se sustenta sobre la idea que ambos conceptos son constructos de recepción, en cuanto los públicos son quienes se forman tales percepciones en función de la conducta y de la información que reciben acerca de una organización (Capriotti, 2009, pp. 93-97). Esto se puede observar claramente en las investigaciones de mercado sobre imagen y reputación. En ambos casos, se estudian las asociaciones, atributos, valores, etc., que cada uno de los públicos tiene sobre las distintas organizaciones. Como ejemplo de esta similitud, se puede observar cómo el mismo sistema de representación gráfica de las asociaciones de un público (un conjunto de atributos valorados a partir de una escala de opciones) puede ser utilizado por Van Riel (2000) para ejemplificar un estudio de reputación, mientras que Dowling (1993) lo utiliza para mostrar una investigación de imagen.

No será hasta 1982 que la revista norteamericana Fortune decidió por primera vez publicar su ya legendario ranking sobre las empresas más admiradas Most Admired Companies, cuando se reconozca de facto el valor que la reputación corporativa aporta a las empresas. Hoy en día, la edición que publica esa investigación es el número más vendido en el año y el listado de empresas que figuran en él continúa siendo el patrón de medida más popular de imagen corporativa en todo el mundo (Ritter, 2013, p. 8).

A partir de ese momento, pero sobre todo durante los años 90 y la primera década del siglo XXI, la proliferación de estudios sobre reputación se multiplica. Estos estudios realizados desde distintas líneas de pensamiento evidencian las diferencias de criterio y teorización de la reputación corporativa. El concepto de reputación va a ir adquiriendo cada vez más peso como elemento fundamental de la gestión empresarial. Muchos autores coinciden en que el cambio de sensibilidad desde la imagen corporativa hacia la reputación se produce porque esta segunda se disocia por primera vez del mundo de la imagen, de la publicidad y la venta, para asociarse al mercado, como fuente de valor y rendimiento financiero para las empresas, pasando a considerarse un activo capaz de general valor para las mismas: Una buena reputación mejorará la capacidad de una empresa para sostener en el tiempo unos rendimientos financieros (Roberts y Dowling (2002). A partir de ese momento, muchas son las investigaciones que trabajan sobre el concepto de reputación en esa línea (Weigelt y Camerer, 1988; Hall, 1992, Rindova y Fombrun, 2001, Dowling, 2002, entre otros. (Villafañe, 2013).

De acuerdo con Rosa Chung, autora muy citada en la literatura sobre reputación, han sido fundamentalmente dos las perspectivas desde las que se ha estudiado la reputación: la perspectiva económica y la del marketing, comunicación y estrategia (Chung, 2005, p.92). Desde la perspectiva económica, la reputación es, en esencia, entendida como la percepción de la probabilidad futura de proteger su cuota de mercado y beneficios (The perceived likelihood that it will defend its markets) (Clark and Montgomery 1998; Weigelt and Camerer 1988; etc.). Varios autores destacan en esta línea de pensamiento donde la reputación cumple claramente un papel de activo y/o recurso intangible de gran relevancia, dada la influencia que tiene en otras variables, como la creación de valor (De Quevedo, 2003; Borraz y Fuentelsaz, 2005; De Quevedo, De la Fuente y Delgado, 2005), y la generación de beneficios empresariales. Dichos beneficios hacen que las organizaciones se esfuercen en la adecuada gestión de la reputación para mejorar sus resultados, su solidez en el medio y largo plazo, y la creación de ventajas competitivas (Martínez y Olmedo, 2010, p.60). Las definiciones que provienen del marketing, la comunicación y la estrategia, la definen básicamente como la impresión acumulada que los stakeholders se forman sobre la compañia, resultado de sus interacciones con ella y de la información recibida sobre la misma. Muchos autores hacen hincapié en la imagen y la identidad corporativa como el corazón de la reputación y ponen el foco en el proceso configurador de la misma como un proceso básicamente comunicativo, donde la percepción cumple un papel fundamental. No obstante, hay voces disonantes. Por tanto, el estudio de la conceptualización de la reputación pasa por dos ámbitos diferenciados.

En primer lugar, desde el ámbito de la comunicación, el marketing y la estrategia. Han sido los teóricos del ámbito de la comunicación y la estrategia empresarial los más prolíficos a lo largo de los últimos 30 años en Europa y EEUU en el estudio de la reputación y la imagen corporativa como las bases de la nueva economía de los intangibles. Cada autor ha incidido en distintos aspectos configuradores de la reputación, pero hay, como es lógico, varios elementos en los que de alguna u otra forma confluyen y que la definen: la percepción, como elemento básico de la reputación y, en un segundo estadio, el reconocimiento; el paso de cierto tiempo como condición para la configuración de esa percepción; y el papel del sujeto emisor y del sujeto receptor como constructores de la reputación.

La consideración de la percepción como elemento básico de la reputación es un aspecto en el que insisten muchos autores en tanto 
En este sentido, Fombrun (1996) delimita el término como una «percepción representativa de la compañía, basada en su actuación en el pasado así como en su proyección futura, lo que permite diferenciarla de otras empresas rivales». El trabajo de Fombrun (1996) avanza respecto a los de otros contemporáneos en lo que se refiere a la concepción del tiempo al introducir la proyección futura de la empresa, de ahí que los elementos básicos que componen la reputación para este autor sean: la actuación pasada de la empresa, las expectativas de futuro, la admiración que despierta, la comparación con los rivales y la percepción. En esta misma línea se centran las aportaciones de Weiss, Anderson y Maclnnis (1999) que entienden la reputación como «una percepción global de alcance por la cual una organización es ayudada a conseguir mayores estimaciones o respeto», y también de Rodríguez (2004) al definirla como «una percepción que se tiene desde el exterior de la empresa sobre una o varias cualidades de ésta». Otro autor que trabaja en esta línea es Larkin (2003), para el que la reputación, "está basada en percepciones de las características, actuaciones y comportamiento de una organización. Esencialmente, la reputación es el reflejo bueno o malo que los grupos de interés ven en un nombre comercial. Implica un juicio de valor acerca de los atributos de la organización y generalmente se establece con el tiempo".

Esta primacía de la percepción como el "corazón" de muchas definiciones de reputación lleva, en algunos casos, a la confusión del concepto de reputación con el de imagen corporativa; no obstante existen notables diferencias entre ambas.

Un segundo estadio de este planteamiento lo encontramos en las aportaciones del Prof. Villafañe $(2004,2013)$ que identifica como elemento básico de la reputación al reconocimiento y no a la percepción, entendiendo que el primero implica un proceso cognitivo resultado de las experiencias y el conocimiento que de una compañía tiene el público. Este enfoque se acerca con mayor exactitud al concepto general de reputación y a la acción de reputar que implica, como hemos visto, la estima del mérito.

El segundo elemento configurador de la reputación es la idea de que se desarrolla a lo largo del tiempo, como indican los autores Martínez y Olmedo (2010, pp. 59-78). En este sentido, Podolny (1993) considera la reputación como una capacidad que se desarrolla a lo largo del tiempo. Gotsi y Wilson (2001) concluyen, tras analizar diferentes definiciones sobre el concepto, que la reputación corporativa es la evaluación total de una organización a través del paso del tiempo. Este aspecto temporal, es decir, su formación a través de la consolidación en el transcurso del tiempo, es recordado también por Barnett et al. (2006), para quienes la reputación son los juicios colectivos de los observadores sobre una organización basados en valoraciones de los impactos financieros, sociales y ambientales atribuidos a la organización con el tiempo. Saxton (1998) hace la misma referencia, al definir la reputación corporativa como la reflexión sobre una organización vista a través de los ojos de los públicos con el paso del tiempo y expresado a través de sus pensamientos y palabras. Por su parte, Villafañe (2013) lo expresa con claridad al afirmar que "una marca es fuerte, creíble, generadora de confianza y de buena reputación para la empresa que la posee en la medida en que no exista disonancia entre las percepciones o expectativas que genera y las experiencias o realidades que entrega, es decir, cuando la marca dice lo que hace y hace lo que dice. La reputación es el resultado de este proceso cuando se mantiene a lo largo del tiempo".

En tercer lugar, la mayor parte de los autores al definir la reputación (y de forma similar otros conceptos relacionados como la imagen y el posicionamiento) la vinculan al ámbito de alguno de los sujetos dentro del proceso general de comunicación, esto es, hacia el emisor 0 el receptor como constructores de la misma.

De acuerdo a Capriotti (2007), se pueden establecer dos grandes concepciones: el enfoque vinculado al emisor (sender-oriented) y el enfoque vinculado al Receptor (receiver-oriented). No obstante, y según el mismo autor, en el proceso general de comunicación, la elaboración e interpretación de la información no es una acción individualizada del emisor (la construcción) y del receptor (la interpretación). Más bien puede considerarse que la construcción de sentido es un proceso de interacción mutuo y compartido entre emisor y receptor. Podemos hablar de un contrato de sentido entre un emisor-organización y unos destinatarios-públicos, en el cual hay una parte que elabora y propone un sentido a la información (el emisor-organización) y otra parte que interpreta y otorga un sentido a la información (los destinatarios-públicos).

Respecto a la consideración del emisor como responsable de la construcción de la reputación parece claro, como hemos visto al principio, que el emisor tiene un papel configurador, es decir, establece con sus actos la configuración de la reputación y la transmisión de la misma. Trasladado al ámbito de la empresa, podemos por tanto afirmar que se trata de un elemento intangible que es configurado y gestionado directamente por la organización y que ésta hace llegar a sus públicos. Tal afirmación pone de manifiesto la existencia de un control directo de la organización sobre ella, que decide el modo de construir tal reputación para sí misma. Sería así la reputación un resultado de la acción y comunicación de la empresa.

Pocos autores reconocen este planteamiento en su definición de la reputación y dotan al emisor -la empresa- como el responsable de la configuración de la misma en tanto que sin acción no cabe relación con un tercero y, por tanto, es imprescindible para su configuración que el emisor implemente una acción y con ello dé la oportunidad al emisor de reconocerla como merecedora de reputación. Tal es el caso de Villafañe (2013), quien sitúa a la reputación como el resultado de comportamientos, de realidades objetivables de una empresa. El autor pone de manifiesto la diferencia que existe entre percepción y reconocimiento en tanto que la primera no requiere de una experiencia por parte del receptor y la segunda sí. Lo que significa que si no es necesaria la experiencia es casi como decir que da igual lo que haga una empresa en tanto que comunique aquello que los públicos quieren escuchar para reconocerla como reputada, esto es, que las acciones de una empresa no son configuradoras de la reputación de la misma, lo cual contradice el propio concepto general de reputación. No obstante, son numerosos los autores que mencionan al emisor como fuente de reputación, pero no configurador de la misma. Es el caso de Fombrun (2001), quien señalaba que la reputación es un activo económico y, por lo tanto, puede ser construida a partir de una serie de acciones y reacciones hacia el entorno en el que las compañías están inmersas. Los autores que defienden esta postura entienden que la reputación es consecuencia de una relación comprometida de la organización para con sus públicos. Entienden que cada organización puede gestionar su reputación directamente por medio de la gestión de su comportamiento y de su comunicación. Fombrun (1996) afirma que la reputación cristaliza los esfuerzos estratégicos y expresivos que las compañias hacen para comunicar su objetivo principal y su identidad a sus públicos. Esta definición, y las anteriores, no hacen sino reforzar la idea de que es el conjunto de comportamientos de la organización a 
lo largo del tiempo el principal responsable de la consolidación de una percepción significativa de sus públicos prioritarios en forma de reputación. Así lo asegura también Dowling (2001) refiriéndose a estos comportamientos significativos (en forma de compromisos) por parte de la organización, cuando define la reputación como el resultado de una imagen positiva de la organización, cuando ésta encierra valores como la autenticidad, la responsabilidad y la integridad, es decir, valores que apelan al compromiso de la entidad con sus públicos y al grado de cumplimiento de sus compromisos. Por tanto, la reputación puede ser gestionada y orientada por la organización en función de sus objetivos. De este modo, los diferentes teóricos entienden la reputación desde un enfoque económico o estratégico y se centran en los beneficios que la gestión de este intangible estratégico reporta a la organización. En paralelo, estos autores hacen referencia al proceso cognitivo que da lugar a su formación por parte de los receptores, dándole un papel muy importante a la percepción del receptor.

Respecto al receptor como sujeto básico de la construcción de la reputación, cabe señalar que buena parte de las definiciones de reputación dan suma importancia a la intervención de los públicos de una organización. Desde este punto de vista, la reputación sería un concepto que deberíamos asociar directamente a la representación mental que los públicos atribuyen (consciente 0 inconscientemente) a una organización. La Reputación se entiende por tanto como resultado de la interpretación del receptor. Así lo asegura Fombrun (1996 y 2001) para quien la reputación corporativa es una representación colectiva de las acciones pasadas de la organización y de sus propuestas de futuro, que describe cómo las audiencias clave interpretan las iniciativas de una entidad y evalúan su capacidad de entregar resultados valorados. Incluso, el autor va más allá en lo que se refiere al peso que se le da al receptor y su percepción como configurador de la reputación, asegurando que la evaluación mental que los stakeholders hacen de las organizaciones está basada en su capacidad para satisfacer sus propios criterios económicos, egoístas y altruistas, y en el impacto que sus múltiples imágenes externas tienen sobre sus stakeholders.

Son numerosos los autores que de un modo u otro se adscriben a esta consideración sobre la reputación corporativa que pone el foco en la interpretación de los receptores. Barnett et al. (2006) concluyen, tras la revisión de las aportaciones de un buen número de teóricos y de profesionales, que la reputación debería enfocarse en el futuro en términos de valoración, juicio, evaluación y opinión. De modo parecido lo entienden Gray y Ballmer (1998), para quienes la reputación corporativa es una valoración de los atributos de la organización, realizada por los públicos. Otros autores, como Roberts y Dowling (2002), afirman ver la reputación como una percepción global del grado en el cual una organización es estimada o respetada, definición que completan asegurando que la reputación no es otra cosa que un atributo general que refleja el grado en el que los públicos externos ven a la entidad como "buena" o "mala".

Las aportaciones de Chun (2005) al estudio de la reputación en base al trabajo de Fombrun y Van Riel (1997), también siguen esta línea de pensamiento que pone el foco en la percepción del receptor como la base de la construcción de la reputación. Chung lo explica, no obstante, estableciendo tres escuelas de pensamiento sobre el concepto de reputación (2005, p.94): 1) evaluativa, donde la reputación se estima según el valor financiero o los resultados económicos de la empresa en el corto plazo, centrándose por tanto en la percepción que tienen los inversores o directivos de las empresas, como sucede en los índices elaborados por Fortune; 2) impresional, que evalúa la reputación a partir de las impresiones obtenidas de trabajadores o consumidores a través de entrevistas, centrándose sólo en un grupo de interés; y 3) relacional, en donde la reputación es el reflejo de las apreciaciones de los distintos grupos de interés, tanto internos (directivos, trabajadores) como externos (consumidores, usuarios). Los trabajos de Chung han sido muy influyentes en tanto que pusieron el foco en que la reputación se definía de forma unívoca tanto desde los públicos internos como externos y ambos se consideran configuradores de la misma. Varios autores son defensores de este mismo planteamiento (Fombrun, 1996; Post y Griffin, 1997; Hatch y Schultz, 2001; Chung y Davies, 2006; etc.) para los que la imagen se distingue de la reputación porque está ligada sólo a los públicos externos y la reputación se conforma por ambos públicos, internos y externos. Como derivada de dicho planteamiento, estos autores identifican como elementos de la reputación a la imagen y la identidad corporativas, y las entrelazan a ambas para configurar la reputación (Chung, 2005, p. 98). Estos planteamientos supusieron un avance en la definición de la reputación y aún hoy en día muchos profesionales siguen esta escuela de pensamiento -escuela relacional-. No obstante, vemos que esta aproximación es un tanto restrictiva puesto que Chung sólo tiene en cuenta la reputación como resultado de la percepción del receptor o público, sea este interno, externo o ambos, y obvia el papel del emisor en la construcción de dicha reputación. Además, la propuesta de Chung analiza la reputación tomando en consideración las distintas metodologías de medición existentes y en base al proceso metodológico que utilizan, pero no profundiza previamente en las características del concepto para posteriormente contrastar si dichas metodologías se ajustan al mismo o no. Otros autores que apoyan una interpretación focalizada en la percepción del receptor como base del fenómeno reputacional son Gotsi y Wilson (2001) que concluyen, tras analizar diferentes definiciones sobre el concepto, que la reputación corporativa es la evaluación total de una organización a través del paso del tiempo. Este aspecto es recordado por Barnett et al. (2006), para quienes la reputación son los juicios colectivos de los observadores sobre una organización basados en valoraciones de los impactos financieros, sociales y ambientales atribuidos a la organización con el tiempo.

Todas estas definiciones, por lo tanto, aunque reconocen el impacto relativo que las decisiones de la propia organización pueden ejercer en la creación y control efectivo de la reputación corporativa, enfatizan el peso sustancial que en la construcción de la misma tienen los receptores (los públicos) y el papel de la percepción. A pesar de ello, el análisis de los autores citados pone de manifiesto su interés central por las posibilidades reales que la organización tiene para ejercer un cierto control en la creación de las percepciones positivas consolidadas en sus públicos, y en los beneficios innegables que esto le puede suponer.

En segundo lugar, desde el ámbito económico - contable. Diferentes teóricos han puesto su foco en la reputación desde puntos de vista relacionados directamente con la gestión empresarial, la contabilidad y las finanzas y la teoría de mercado. Porque el peso que ha adquirido la reputación en las grandes compañías en las últimas décadas viene derivado de su valor económico y su valor estratégico: "La reputación no se puede copiar y no se fuga con la marcha de los directivos. Es una decisión que determina el comportamiento y la gestión de las operaciones. Por tanto, la reputación es en sí misma una estrategia de crecimiento" (Manfredi y Cachinero, 2013, pp. 61-73).

Existe un consenso general entre los teóricos y nadie pone en duda su importancia como intangible fundamental a tomar en consideración a la hora de gestionar una empresa, y herramienta clave en la creación de valor para todos sus stakeholders (Porter y Kramer, 2011, pp. 12-17). La reputación es así un recurso intangible tan importante, que su medida y cuantificación permite manejar lo que es con frecuencia el valor dominante en la evaluación total de una empresa. $Y$ así es reconocida por muchos de los primeros ejecutivos de grandes empresas de cuatro grandes economías mundiales (Estados Unidos, Reino Unido, Brasil y China), según una investigación realizada por Weber Shandwick, que consideran que la reputación es el principal factor para sostener el valor en bolsa de sus compañías, por encima del propio 
estado financiero de la firma ( $60 \%$ del valor, según los CEO es atribuible a la reputación, siendo los brasileños los más optimistas en este sentido, otorgando un $76 \%$ ). Incluso un $58 \%$ de ellos prefiere obtener una cobertura mediática que hable de su reputación y el respeto que merece su compañia en la sociedad, frente a un $37 \%$ que sigue prefiriendo leer noticias sobre las previsiones de un incremento futuro del valor de su acción (Reputation Institute, 2011).

Pero la reputación, ¿es un activo o un recurso intangible? Tal y como ponen de manifiesto Cañibano y Gisbert (2003, p. 190), la normativa contable española no recogía ninguna definición sobre el concepto de "activo intangible", tan solo se limitaba a inventariar todos los elementos clasificados bajo la rúbrica de "inmovilizado inmaterial" así como a describir el tratamiento contable para cada uno de ellos. La definición del concepto de "activo intangible" recogida en la normativa contable de otros organismos internacionales como el IASB, va más allá de una simple definición, al recogerse en ésta, de forma implícita, los requisitos generales de reconocimiento para los activos de esta naturaleza. El nuevo PGC, continúa sin ofrecer una definición específica de los "activos intangibles", si bien la norma $5^{\text {a }}$ de la segunda parte del nuevo PGC, dedicada a las normas de registro y valoración del inmovilizado intangible, hace referencia a la definición de activo del marco conceptual así como a la característica de "identificabilidad", como parte de los requisitos necesarios de reconocimiento que en definitiva permiten, al igual que en la NIC 38 (2004), discriminar entre recursos vs. activos intangibles .

Bajo el marco conceptual del nuevo PGC, los activos son aquellos "bienes, derechos y otros recursos controlados económicamente por la empresa resultantes de sucesos pasados, de los que se espera que la empresa obtenga beneficios o rendimientos económicos en el futuro1". (PGC 2007, Marco conceptual, $4^{\circ}$ párr. 1). No obstante, para su reconocimiento, los activos de naturaleza intangible no sólo deben cumplir con la definición anterior, sino que además, como ya ha quedado señalado, es necesario que sean "identificables". Se trata de un concepto nuevo, hasta ahora ausente en nuestro ordenamiento contable, cuyo cumplimiento por el activo intangible en cuestión implica bien su procedencia de derechos legales o contractuales, bien su separabilidad, es decir, la posibilidad de que el activo pueda ser arrendado, vendido, intercambiado etc.; en definitiva, separado de la empresa (PGC 2007, Normas de registro y valoración, $5^{a}$ párr. 1).

Pero, ¿es la reputación un activo de estas características? Las diferentes aproximaciones teóricas que venimos estudiando ponen de manifiesto como existe un nexo inseparable entre la empresa y su reputación. Algunos autores lo denominan movilidad imperfecta, refiriéndose a que los activos que cumplen este atributo no se pueden transferir, vender, adquirir o comercializar, puesto que son intrínsecos y propios a la firma, tal y como le sucede a la reputación. Parece inviable definir la reputación como un activo tomando en consideración la normativa contable actual. Más bien, podemos hablar de la reputación como un recurso o una capacidad dinámica.

La Teoría de los Recursos y Capacidades tiene un papel destacado en el desarrollo de los fundamentos teóricos de la reputación empresarial en su etapa más reciente y prolífica, desarrollada en la década de los 90 y en los inicios del siglo XXI. Este enfoque ha introducido dos nuevos conceptos de estudio: los recursos y capacidades que tiene la empresa, caracterizando aquéllos que le ayudan a crear ventajas competitivas y a hacerlas sostenibles. La reputación no ha sido ajena a esta consideración y en este sentido, trabajos como el de Barney (2001) y Borraz y Fuentelsalz (2005) ayudan a esclarecer sus principales características y a entender este concepto como un recurso, una capacidad organizativa y un activo intangible (Hall, 1992 y 1993; Fombrun, 1996) siendo, como tal, fuente de ventaja competitiva (Barney, 1991; Grant, 1991; Hall, 1992; Amit y Schoemaker, 1993; Helfat y Peteraf, 2003, Teece et al, 1997). Desde este enfoque, surge la problemática entre considerar la reputación corporativa como un recurso o como una capacidad. Aunque es común identificar la reputación como un recurso de la empresa (Grant, 1991; Hall, 1992), para algunos autores se puede clasificar como una capacidad (Borraz y Fuentelsaz, 2005), en tanto en cuanto integra una serie de recursos que la empresa pone en juego de modo lo suficientemente hábil como para crear una identidad empresarial que se puede transmitir al exterior y difundir de modo interno (Teece y otros, 1997). Es por ello que Barney (1999) la identifica como una de las principales capacidades organizativas. Como capacidad organizativa, la reputación es heterogénea puesto que cada organización dispone de un conjunto único de recursos que varían según el momento del tiempo en que se estimen (Barney, 1991; Helfat y Peteraf, 2003; Ventura, 1996; Deephouse, 2000). La reputación actual de una empresa se construye o acumula en un contexto histórico y en unas circunstancias únicas, que raramente se van a volver a repetir. Por tanto, no es algo que surge espontáneamente, sino que necesita tiempo para conseguirse, lo que implica el análisis del pasado, del presente y también la proyección futura (tal y como veíamos anteriormente). Por todo ello, la reputación llega a ser altamente específica para cada firma.

De las características descritas, se deduce que la reputación es fuente de ventaja competitiva, pues además cumple las cualidades de un recurso estratégico (Barney, 1991): (i) valor o relevancia, (ii) escasez, (iii) carácter específico, junto a las de (iv) complejidad, (v) lenta acumulación, y (vi) complementariedad. Por todo ello, parece ajustado considerar la reputación como un recurso estratégico (Barney, 1991) y una capacidad dinámica que se debe incentivar continuamente (Amit y Schoemaker, 1993; Teece y otros, 1997; Borraz y Fuentelsaz, 2005).

\section{Conclusiones: nueva propuesta conceptual de Reputación corporativa}

De acuerdo a lo expuesto anteriormente, se pueden identificar distintos elementos configuradores del concepto de reputación que son comunes entre muchos teóricos y profesionales de la misma; por ello, podemos adentrarnos en una posible definición de consenso que permita abordar la reputación desde el conocimiento para sacar el mayor rendimiento a su gestión. Esta es la propuesta de la autora del presente artículo que somete a consideración de teóricos y profesionales:

Reputación corporativa: recurso intangible propio de la empresa que se materializa en el comportamiento de la misma y que requiere de un cierto tiempo para su configuración, que es reconocido por sus públicos como generador de valor en tanto que se ajusta a lo que éstos estiman como meritorio de la misma. 


\section{Bibliografía}

Alloza, A, Carreras, A y Carreras (2013): Reputación Corporativa. Madrid: LID Editorial.

Álvarez, Jesús T (2013): Manejo de la comunicación organizacional. Madrid: Díaz de Santos.

Amit, R. y Schoemaker, P. J. H. (1993): «Strategic Assets and Organizational Rent», Strategic Management Journal, vol. 14, págs. 33-46.

Balmer, J.M.T. (2001): Corporate identity, corporate branding and corporate marketing: seeing through the fog. European Journal of Marketing, 35(3/4)

Balmer, J. M. T. y Greyser, S. A. (2006): Corporate marketing: Integrating corporate identity, corporate branding, corporate communications, corporate image and corporate reputation, European Journal of Marketing, Vol. 40, No. 7/8, pp. 730-741.

Barnett, M. L., Jermier, J. M. y Lafferty, B. A. (2006): Corporate reputation: The definitional landscape, Corporate Reputation Review, Vol. 9 , No. 1, pp. 26-38.

Barney, J.B., (1991): «Firm Resources and Sustained Competitive Advantage», Journal of Management, vol. 17, núm. 1, págs. 99-120.

Borraz, J. y Fuentelsaz, L. (2005): «La Gestión del Ciclo de Vida de las Capacidades: Un Análisis para el Caso de la Reputación», IV Iberoamerican Academy of Management, 8-11 de diciembre, Lisboa.

Bromley, D. B. (2002): Comparing corporate reputations: League tables, quotients, benchmarks, or case studies?, Corporate Reputation Review, Vol. 5, No. 1, pp. 35-50.

Brown, T.J y Dacin, P.A. (1997): The company and the product: corporate associations and consumer product responses. Journal of Marketing, vol. 61.

Cañibano, I y Gisbert, A. (2007). "Los activos intangibles en el nuevo Plan General Contable". Revista del Instituto de Estudios Económicos, $n^{0} 2-3$.

Capriotti, P (2009): Branding corporativo. Fundamentos para la gestión estratégica de la identidad corporativa; Chile, Libros de Empresa.

Caruana, A. (2008): An attitudinal measure of corporate reputation, en Melewar, T. C., (ed.), Facets of corporate identity, communication and reputation, Abingdon, Oxon, UK; New York, NY, Routledge, pp. 197-210.

Caruana, A. y Chircorp, S. (2000): Measuring corporate reputation: A case example, Corporate Reputation Review, Vol. 3, No. 1, pp. $43-57$. Chung, R. (2005): Corporate reputation: Meaning and measurement, International Journal of Management Review, Vol. 7, No. 2, pp. 91109.

De Quevedo, E. (2003): Reputación y Creación de Valor. Una Relación Circular, Madrid, Paraninfo.

De Quevedo, E.; De La Fuente, J. M. y Delgado, J. B. (2005), «Reputación Corporativa y Creación de Valor. Marco Teórico de Una Relación Circular», Investigaciones Europeas de Dirección y Economía de la Empresa, vol. 11, núm.2, págs. 81-97.

Deephouse, D. L. (2000): Media reputation as a strategic resource: An integration of mass communication and resource-based theories, Journal of Management, Vol. 26, No. 6, pp. 1091-1112.

Grant, R. M. (1991), "The Resource-Based Theory of Competitive Advantage: Implications for Strategy Formulation», California Management Review, vol.33, núm. 3, págs. 233-258.Gotsi, M. y Wilson, A. M. (2001): Corporate reputation: Seeking a definition, Corporate Communications, Vol. 6, No. 1, pp. 24-30.

Hall, R. (1992): The Strategic Analysis of Intangible Resources, Strategic Management Journal, vol. 13. pp. 135-144.

Hatch, M.J. y Schultz, M. (2000): Scaling the tower of Babel: relational differences between identity, image and culture in organizations. In Larsen, M.H. (ed.), The Expressive Organization: Linking Identity, Image and Culture in Organizations. New York: Oxford University Press.

Helm, S. (2005): Designing a formative measure for corporate reputation, Corporate Reputation Review, Vol. 8, No. 2, pp. 95-109.

Helfat, E. y Peteraf, M. A. (2003), «The Dynamic Resource - Based View: Capability Lifecycles», Strategic Management Journal, vol. 24, núm. 10, págs. 997-1010.

Herbig, P. y Milewicz, J. W. 1993. The relationship of reputation and credibility to brand success. The Journal of Consumer Marketing, 10(3), p. 18.

Larkin, J. (2003). Strategic Reputation Risk Management, Reino Unido, Palgrave MacMillan, p. 32.

Manfredi, Juan Luis y Cachinero, Jorge. ¿Tecnocracia o política?: reputación, transparencia y liderazgo. Reputación y Liderazgo d+i Llorente \& Cuenca, 2013, febrero.

Martineau, P (1958): Sharper focus for the corporate image. Harvard Business Review, vol.36.

Martínez, I y Olmedo, I (2010): Revisión teórica de la reputación en el entorno empresarial. Cuadernos de Economía y Dirección de la Empresa. Núm. 44, septiembre 2010.

Podolny, J. M. (1993), «A Status-Based Model of Market Competition», American Journal of Sociology, vol. 98, núm. 4, págs. 829-872.

Ponzi, L. J., Fombrun, C. J. y Gardberg, N. A. (2011): RepTrak ${ }^{T M}$ Pulse: Conceptualizing and validating a short-form measure of corporate reputation, Corporate Reputation Review, Vol. 14, No. 1, pp. 15-35.

Porter ME, Kramer MR. Creating shared value. Harvard Business Review, 2011, January-February.

Pruzan, P. 2001. Corporate reputation: Image and identity. Corporate Reputation Review, 4(1), pp. 50-64.

Real Academia Española (2001): Diccionario de la Lengua Española. Vigésima segunda edición.

Reputation Institute. Welcome to the reputation economy, where reputation management is not optional. Reputation Intelligence, 2011, volume 3 , issue 2, summer 5-9.

Ritter, Michael (2013): El valor del capital reputacional: por qué la opinión que el público tiene de su empresa es un activo estratégico; Buenos Aires, Ritter \& Partners,

Rodríguez, J. M. (2004), «Percepción y Medida en la Reputación Empresarial», Economía Industrial, núm. 357, págs. 117-129.

Schwaiger, M. (2004): Components and parameters of corporate reputation-An empirical study, Schmalenbach Business Review, Vol. 56, No. 1, pp. 46-71.

Shenkar, O. y Yuchtman-Yaar, E. 1997. Reputation, image, prestige, and goodwill: An interdisciplinary approach to organizational standing. Human Relations, 50(11): 1361-81.

Teece, D. J.; Pisana, G. y Shuen, A. (1997), «Dynamic Capabilities and Strategic Management», Strategic Management Journal, vol. 18, núm. 7, págs. 509-533.

Van Riel, C. B. M. y Fombrun, C. J. (2007): Essentials of corporate communication: Implementing practices for effective reputation management, London; New York, Routledge.

Villafañe, J. (2004): La buena reputación. Claves del valor intangible de las empresas. Madrid: Ediciones Pirámide.

Walker, Joseph M. (1999): La Grecia Antigua. Madrid: Edimat Libros. 
Weigelt, K. y Camerer, C. (1988): Reputation and Corporate Strategy: A Review of Recent Theory and Applications. Strategic Management Journal, 9(5): 443, 12 pgs.

Weiss, A. M.; Anderson, E. y Maclnnis, D. J. (1999): «Reputation Management as a Motivation for Sales Structure Decisions», Journal of Marketing, vol. 63, núm. 4, págs. 74-99.

Cómo citar este artículo en bibliografías - How to cite this article in bibliographies / references:

FERRUZ GONZÁLEZ, S. A. (2017): "Conceptualización de la Reputación Corporativa. Nuevo enfoque y propuesta”. En Revista de la Asociación Española de Investigación de la Comunicación, vol. 4, número 7 , pp. 130-137. 